\title{
Intensive Home Hemodialysis Results in Regression of Left Ventricular Hypertrophy and Better Clinical Outcomes
}

\author{
Emilie Trinh Christopher T. Chan \\ Division of Nephrology, University Health Network, Toronto, Ont., Canada
}

\section{Key Words}

Intensive hemodialysis · Home hemodialysis · Left ventricular mass - Left ventricular hypertrophy · Regression

\begin{abstract}
Background: Left ventricular hypertrophy (LVH) is an independent risk factor for mortality and cardiovascular events in patients with end-stage renal disease. Studies have shown that frequent hemodialysis leads to LVH regression, but the impact of left ventricular mass (LVM) regression on clinical outcomes remains unknown. Methods: This observational cohort study assessed the impact of $\mathrm{LVH}$ regression on the composite outcome of time to all-cause mortality, technique failure or cardiovascular hospitalization in patients on home hemodialysis. LVH regression was defined as either a reduction of more than $10 \%$ in LVM in patients with LVH at baseline or prevention of LVH in those without LVH at baseline. Risk factors associated with progression of LVM were also examined. Results: We studied 144 intensive hemodialysis patients between 1999 and 2012 with a mean follow-up of 4.7 years. Eighty-seven patients (60.4\%) had LVH regression or prevention and 57 patients (39.6\%) had LVH progression. In a multivariate analysis, smoking (OR $2.78,95 \% \mathrm{Cl} 1.06-$ 7.36) and presence of $\mathrm{LVH}$ at baseline (OR $2.21,95 \% \mathrm{Cl} 1.06-$ 4.59) were significant predictors for LVM progression. Sixteen patients (18.4\%) in the regressor group and 19 patients
\end{abstract}

(33.3\%) in the progressor group developed the composite end point. When adjusted for age and diabetes, regression was significantly associated with a decreased risk (hazards ratio (HR) $0.42,95 \% \mathrm{Cl} 0.21-0.84$ ) for the composite end point. Regression was also significantly associated with a decreased risk of death in the adjusted analysis (HR 0.20,95\% $\mathrm{Cl}$ 0.06-0.67). Conclusions: Regression of LVH with intensive hemodialysis is associated with favorable clinical outcomes.

(c) 2016 S. Karger AG, Basel

\section{Introduction}

Cardiovascular disease remains the leading cause of morbidity and mortality among end-stage renal disease (ESRD) patients, accounting for $38 \%$ of all fatalities $[1,2]$. There has been increasing evidence that left ventricular hypertrophy (LVH) is an independent risk factor for mortality and cardiovascular events with important prognostic value in the ESRD population [3-5]. In fact, LVH increases in prevalence with progressive renal function decline, present in up to $85 \%$ of incident dialysis patients [6-8]. LVH in ESRD is multifactorial in origin; hypertension, vascular calcification, volume overload, anemia, hyperparathyroidism, inflammation, high sympathetic activity and various other metabolic and humoral changes having all been implicated in the pathophysiology [2, 4, 5, 9-13].

\section{KARGER}

E-Mail karger@karger.com

www.karger.com/ajn
(C) 2016 S. Karger AG, Basel

0250-8095/16/0444-0300\$39.50/0
Dr. Christopher T. Chan

Division of Nephrology, University Health Network

200 Elizabeth Street, 8N Room 846

Toronto, ON M5G 2C4 (Canada)

E-Mail christopher.chan@uhn.ca 
Studies in conventional hemodialysis and peritoneal dialysis have shown that LVH progresses with time in most patients $[4,14,15]$. In contrast, there has been many studies in recent years demonstrating that frequent hemodialysis (short-daily or long-nocturnal) leads to LVH regression along with improvements in blood pressure control, abnormalities of mineral metabolism, sleep quality and quality of life [16-21]. In the Frequent Hemodialysis Network Daily Trial, 245 patients were randomized to $6 \mathrm{X} /$ week (short-daily or nocturnal) or $3 \mathrm{X} /$ week hemodialysis [22]. Left ventricular mass (LVM), measured by cardiac MRI, decreased with frequent hemodialysis compared to control in both daily and nocturnal trials, although a significant difference was observed only in the larger short-daily group, likely owing to the larger sample size [22].

Several studies have demonstrated improved clinical outcomes with LVH regression in different patient populations. In fact, in 161 in-center hemodialysis patients, Zoccali et al. [4] showed a graded relationship between the rate of increase in LVM and adverse outcomes, with a $1 \mathrm{~g} / \mathrm{m}^{2.7} /$ month increase in LVM index (LVMI) associated with a $62 \%$ increased risk of fatal and nonfatal cardiovascular events. London et al. [23] also demonstrated that the regression of LVM had a favorable impact on survival in conventional hemodialysis patients, with a $10 \%$ LVM decrease associated with decreased all-cause and cardiovascular-related mortality. Furthermore, a meta-analysis in patients with hypertension also showed that LVH regression was independently associated with a reduction in cardiovascular events [24]. Similarly, a recent study in renal transplant recipients also showed improved outcomes with LVH regression [25]. However, the impact of regression of LVM in the setting of more frequent intensive hemodialysis remains unknown.

\section{Objective}

The purpose of this study was to determine whether regression of $\mathrm{LVH}$ with intensive home hemodialysis is associated with improved clinical outcomes and to examine the different risk factors associated with regression or progression of LVM.

\section{Methods}

We performed a retrospective cohort study in patients on intensive home hemodialysis at the Toronto General Hospital from January 1, 1999, to July 1, 2012. Exclusion criteria included patients on home hemodialysis for $<1$ year or patients with missing echocardiographic information at baseline or upon follow-up. In- tensive hemodialysis was defined as $\geq 16$ h of hemodialysis therapy per week based on the prescribed regimen on the last day of home hemodialysis training. A standard initial regimen consisted of $\geq 5$ nocturnal sessions of hemodialysis per week of at least $7 \mathrm{~h}$ duration. We then classified patients based on regression or progression of LVH in their following echocardiograms.

Echocardiograms, performed before a hemodialysis session, were done at baseline and subsequently at yearly intervals. LVM measurements included the LV posterior wall thickness, interventricular septal thickness and mean wall thickness calculated by the $2 \mathrm{D}$ method. $\mathrm{LVH}$ was defined using the recent recommendations from the American Society of Echocardiography and European Association of Cardiovascular Imaging - a LVMI $>102 \mathrm{~g} / \mathrm{m}^{2}$ in men and $>88 \mathrm{~g} / \mathrm{m}^{2}$ in women - measured using the $2 \mathrm{D}$ method [26].

Regression of LVH ('regressors') was defined as a reduction of more than $10 \%$ in LVM in the last follow-up echocardiogram in patients with $\mathrm{LVH}$ at baseline, and continued absence of LVH in patients without LVH at baseline. Progression of LVH ('progressors') was defined as a reduction of less than $10 \%$ or increase in LVM in the last follow-up echocardiogram in patients with LVH at baseline, and development of LVH in the last follow-up echocardiogram in patients without LVH at baseline. A $10 \%$ cutoff was used to define regression as London et al. [23] previously demonstrated favorable outcomes with a $10 \%$ LVM decrease in hemodialysis patients.

The primary outcome was the composite outcome of time to all-cause mortality, technique failure or cardiovascular hospitalization from the initiation of the modality. Technique failure was defined as a permanent switch to another renal replacement modality (conventional hemodialysis or peritoneal dialysis), and a cardiovascular event was defined as either myocardial infarction or unstable angina or arrhythmia or heart failure or stroke.

Covariates considered to be critically relevant included age, gender, race, body mass index, cause of ESRD, duration of ESRD, first vascular access type, type of renal replacement therapy prior to intensive hemodialysis and coexisting medical conditions (diabetes, smoking, coronary artery disease, hypertension, cerebrovascular disease and peripheral vascular disease). Antihypertensive therapies at baseline and after 1 year of intensive hemodialysis were also documented.

\section{Statistical Analysis}

Baseline demographics and clinical characteristics are presented as means \pm SD or proportions, as appropriate. Comparisons were tested using the chi-square or Fisher's exact test for categorical variables, and Student $t$ test for continuous variables. KaplanMeier plots are presented to evaluate the time to composite outcome (death, treatment failure or cardiovascular hospitalization) in regressors and progressors. To provide an estimate of LVH regression on clinical outcome after adjustment for other variables, a Cox regression model was used. $\mathrm{p}$ values of $<0.05$ were considered statistically significant. All analyses were performed using SPSS version 20.0 (IBM Corp., USA).

\section{Results}

A total of 144 patients were included in our cohort after excluding the following patients: $<1$-year follow-up $(\mathrm{n}=31)$ and missing echocardiogram information $(\mathrm{n}=$ 


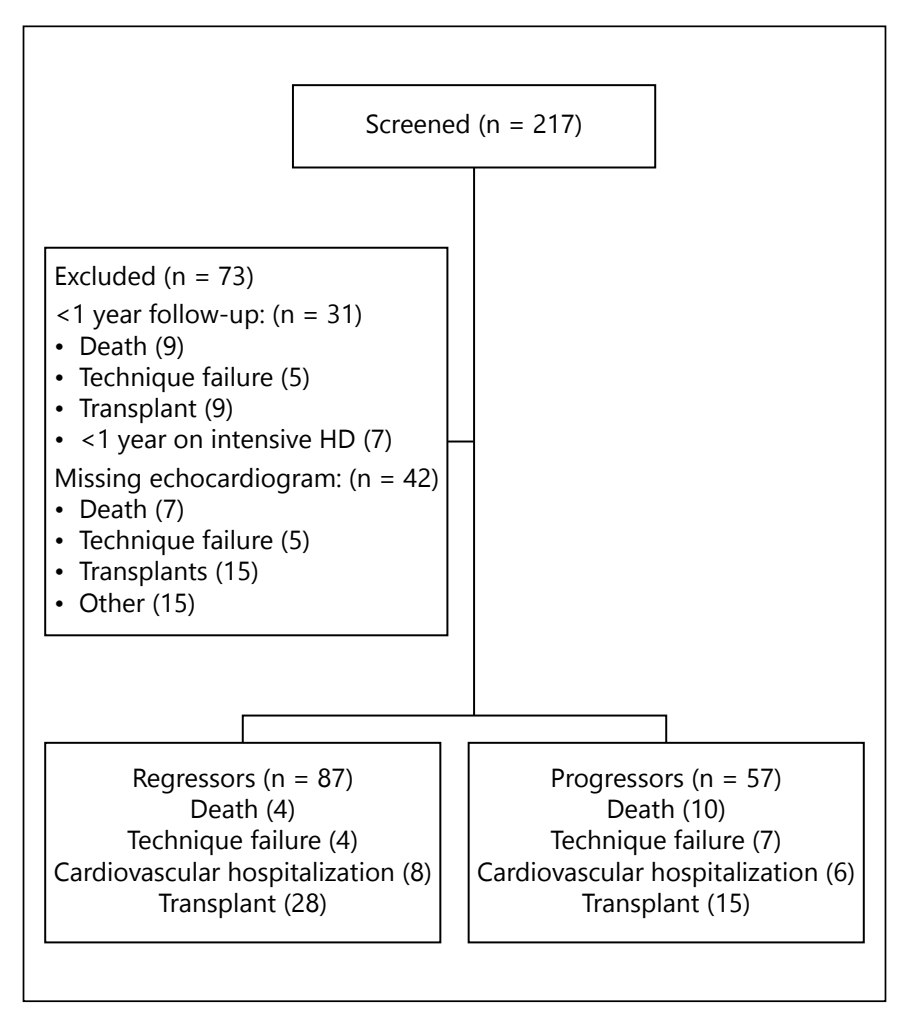

Fig. 1. Patient flow diagram is illustrated.

42). Figure 1 illustrates the patient flow diagram. The mean follow-up was $4.7 \pm 3.0$ years. The baseline demographics of the cohort are summarized in table 1.

\section{LVH Status at Baseline}

At baseline, 82 patients (56.9\% of the cohort) had LVH. Baseline characteristics of patients with and without $\mathrm{LVH}$ at time of initiation of intensive hemodialysis are presented in table 2. Patients with LVH were older (mean age 46.6 vs. 41.3 years, $\mathrm{p}=0.013$ ), more likely to have had a failed kidney transplant as a cause for ESRD (29.3 vs. $14.5 \%, \mathrm{p}=0.029)$ and more likely to be diabetic ( 28.0 vs. $14.5 \%, \mathrm{p}=0.050$ ). Patients with LVH were also treated with a higher number of antihypertensive medications (mean 2.03 vs. $1.44, \mathrm{p}=0.020$ ) with a higher proportion of patients on $>2$ drugs ( 65.8 vs. $41.0 \%, p=0.003$ ). All other baseline characteristics were not significantly different.

\section{Regressors vs. Progressors}

After follow-up, 87 patients (60.4\%) developed LVH regression or prevention and 57 patients developed $\mathrm{LVH}$ progression (39.6\%). Characteristics of regressors and progressors are presented in table 3. Progressors were more likely to have LVH at baseline ( 68.4 vs. $49.4 \%, \mathrm{p}=$ $0.024)$. In fact, in patients without LVH at baseline, there were 18 progressors $(29.0 \%)$ while, in patients with $\mathrm{LVH}$ at baseline, there were 39 progressors (47.6\%). Progressors were also more likely to be smokers ( 22.8 vs. $9.2 \%$, $\mathrm{p}=0.024)$. In regards to antihypertensive therapy, while there was a non-statistically significant higher proportion of progressors on $>2$ drugs at baseline, antihypertensive therapy was not different between both groups after 1 year on intensive hemodialysis. In fact, $81.2 \%$ of regressors and $81.5 \%$ of progressors either achieved a decrease in number of antihypertensive drugs or remained off blood pressure medications. Similar, only $21.2 \%$ of the regressors and $18.5 \%$ of the progressors remained on $>2$ drugs compared to 48.8 and $64.8 \%$, respectively, at baseline. All other baseline characteristics were not significantly different between both groups. The mean rate of regression was $-14.1 \pm 12.2 \mathrm{~g}$ per year in regressors with $\mathrm{LVH}$ at baseline.

In a multivariate analysis, smoking history (OR 2.78, 95\% CI 1.06-7.36, $\mathrm{p}=0.039)$ and presence of $\mathrm{LVH}$ at baseline (OR 2.21, 95\% CI 1.06-4.59, $\mathrm{p}=0.033$ ) were significant predictors for progression (table 4). Age and diabetes were not significant predictors.

\section{Effect of LVH Regression on Clinical Outcomes}

Sixteen patients $(18.4 \%)$ in the regressors group as compared 19 patients (33.3\%) in the progressors group developed the composite end point of death, technique failure or cardiovascular hospitalization. Four deaths $(4.6 \%)$ occurred in the regressors group while 9 deaths $(17.5 \%)$ occurred in the progressors group. Four patients $(4.6 \%)$ experienced technique failure in the regressors group compared to 7 patients $(12.3 \%)$ in the progressors. In regards to cardiovascular hospitalization, 8 patients $(9.2 \%)$ experienced this end point in the regressors compared to 6 patients (10.5\%) in the progressors. A total of 43 patients were transplanted during the time of follow-up (32.2\% of the regressors and $26.3 \%$ of the progressors). Kaplan-Meier curves with log-rank test showed improved survival in patients with LVH regression compared to progression with regards to both the composite outcome ( $\mathrm{p}=0.046$; fig. 2$)$ and death $(\mathrm{p}=$ 0.009; fig. 3).

In an unadjusted Cox regression analysis, LVH regression was significantly associated with a lower risk of the primary composite outcome (hazard ratio (HR) 0.51, 95\% CI 0.26-0.99). When adjusted for age and diabetes, $\mathrm{LVH}$ regression remained significantly associated with a decreased risk (HR 0.42, 95\% CI 0.21-0.84) while age (HR 
Table 1. Baseline characteristics of the cohort

\begin{tabular}{|c|c|}
\hline Age, years, mean $\pm S D$ & $44.3 \pm 12.9$ \\
\hline Male sex, n (\%) & $91(63.2)$ \\
\hline \multicolumn{2}{|l|}{ Race, n (\%) } \\
\hline White & $88(61.1)$ \\
\hline Asian & $18(12.5)$ \\
\hline Black & $12(8.3)$ \\
\hline Other & $26(18.1)$ \\
\hline $\mathrm{BMI}, \mathrm{kg} / \mathrm{m}^{2}$, mean $\pm \mathrm{SD}$ & $25.4 \pm 6.2$ \\
\hline \multicolumn{2}{|l|}{ Cause of ESRD, n (\%) } \\
\hline Diabetic nephropathy & $19(13.2)$ \\
\hline Glomerulonephritis & $47(32.6)$ \\
\hline Hypertensive nephrosclerosis & $8(5.6)$ \\
\hline Polycystic kidney disease & $12(8.3)$ \\
\hline Other & $58(40.3)$ \\
\hline \multicolumn{2}{|l|}{$\begin{array}{l}\text { Type of renal replacement therapy prior to } \\
\text { intensive hemodialysis, } \mathrm{n}(\%)\end{array}$} \\
\hline Chronic kidney disease not on dialysis & $41(28.5)$ \\
\hline Non-intensive hemodialysis & $61(42.4)$ \\
\hline Peritoneal dialysis & $9(6.2)$ \\
\hline Renal transplantation & $33(22.9)$ \\
\hline \multicolumn{2}{|l|}{ Initial access type, $\mathrm{n}(\%)$} \\
\hline $\mathrm{CVC}$ & $67(46.5)$ \\
\hline AVF & $69(47.9)$ \\
\hline AVG & $8(5.6)$ \\
\hline Duration of ESRD, years, mean \pm SD & $6.5 \pm 8.4$ \\
\hline Presence of LVH at baseline, $\mathrm{n}(\%)$ & $82(56.9)$ \\
\hline LVM at baseline, $g$, mean \pm SD & $196.4 \pm 71.0$ \\
\hline LVMI at baseline, $\mathrm{g} / \mathrm{m}^{2}$, mean $\pm \mathrm{SD}$ & $108.1 \pm 36.4$ \\
\hline \multicolumn{2}{|l|}{ Co-existing medical conditions, $\mathrm{n}(\%)$} \\
\hline Diabetes & $32(22.2)$ \\
\hline Smoking history & $21(14.6)$ \\
\hline Hypertension & $122(84.7)$ \\
\hline Coronary artery disease & $17(11.8)$ \\
\hline Peripheral vascular disease & $9(6.2)$ \\
\hline Stroke & $11(7.6)$ \\
\hline \multicolumn{2}{|l|}{ Baseline blood pressure therapy } \\
\hline Number of antihypertensives, mean \pm SD & $1.77 \pm 1.43$ \\
\hline Patients on $>2$ antihypertensives, $\mathrm{n}(\%)$ & $77(55.0)$ \\
\hline RAAS blockade/CCB/ $\beta$-blocker, $\%$ & $43.6 / 49.3 / 50.7$ \\
\hline \multicolumn{2}{|l|}{ 1-Year blood pressure therapy } \\
\hline Number of antihypertensives, mean \pm SD & $0.73 \pm 0.94$ \\
\hline Patients on $>2$ antihypertensives, $\mathrm{n}(\%)$ & $28(20.1)$ \\
\hline RAAS blockade/CCB/ $\beta$-blocker, $\%$ & $18.7 / 13.6 / 37.4$ \\
\hline
\end{tabular}

1.04, 95\% CI 1.01-1.07) and diabetes (HR 2.78, 95\% CI 1.32-5.82) were significant predictors of developing the composite end point (table 5).

On the basis of mortality alone, LVH regression was also significantly associated with a decreased risk of death in the unadjusted analysis (HR 0.24, 95\% CI 0.08-0.77) and this remained significant after adjustment for age and diabetes (HR 0.20, 95\% CI 0.06-0.67; table 6).

Regression of LVH in Intensive

Hemodialysis

\section{Discussion}

The present study is the first study to demonstrate that regression of LVH leads to favorable clinical outcomes in patients on intensive home hemodialysis. In fact, our study showed that patients on home hemodialysis with regression or prevention of $\mathrm{LVH}$ had a $58 \%$ lower risk of the composite end point of death, technique failure or cardiovascular hospitalization during a mean follow-up of 4.7 years compared with patients with progression or development of LVH. With regards to mortality alone, $\mathrm{LVH}$ regression was associated with an $80 \%$ decreased risk. Improved survival associated with regression also occurred later suggesting that the time for cardiac remodeling to occur with LVM regression led to a favorable long-term mortality benefit.

Furthermore, regression or prevention of LVH was seen in about two-thirds of patients after initiation of home hemodialysis. In fact, in patients without LVH at baseline, $29.0 \%$ of patients progressed to developing $\mathrm{LVH}$, in contrast to $47.6 \%$ of patients with the presence of LVH at baseline. The significant risk factors identified for LVM progression were the presence of baseline LVH and smoking history. While there was a non-significant trend of a higher proportion of patients with $>2$ antihypertensive drugs at baseline in the progressors group, this is likely related to the higher proportion of patients with baseline LVH. In fact, after 1 year of intensive hemodialysis, both groups achieved a similar significant reduction in the use of antihypertensive medications, thus suggesting that progression or regression of $\mathrm{LVH}$ was mediated by factors independent of blood pressure in this cohort.

These results highlight the important prognostic implication of $\mathrm{LVH}$ regression or prevention in patients on intensive home hemodialysis, regardless of therapeutic strategy. Our study also emphasizes the clinical relevance of serial measurements of LVM in these patients. Moreover, our results show that LVH regression or prevention may be achieved in a substantial proportion of patients with intensive more frequent hemodialysis, regardless of renal replacement therapy modality prior to initiation. These results are also consistent with other studies demonstrating improved LVM with intensive hemodialysis $[16,20-22]$. This is in contrast to studies in peritoneal dialysis or conventional hemodialysis, which have shown that LVH develops and progresses in the majority of patients with time $[4,14]$. The present study's finding of an independent and strong association between LVH regression and improved clinical outcomes is equally comple- 
Table 2. Characteristics of patients with and without LVH at baseline

\begin{tabular}{|c|c|c|c|}
\hline & $\begin{array}{l}\text { No LVH at baseline } \\
(\mathrm{n}=62)\end{array}$ & $\begin{array}{l}\text { LVH at baseline } \\
(\mathrm{n}=82)\end{array}$ & $\mathrm{p}$ value \\
\hline Age, years, mean $\pm \mathrm{SD}$ & $41.3 \pm 13.3$ & $46.6 \pm 12.2$ & 0.013 \\
\hline $\mathrm{BMI}, \mathrm{kg} / \mathrm{m}^{2}$, mean $\pm \mathrm{SD}$ & $25.3 \pm 6.4$ & $25.5 \pm 6.1$ & 0.890 \\
\hline Type of renal replacement therapy prior to intensive hemodialysis, $n(\%)$ & & & 0.029 \\
\hline Chronic kidney disease not on dialysis & $21(33.9)$ & $20(24.4)$ & \\
\hline Renal transplantation & $9(14.5)$ & $24(29.3)$ & \\
\hline Initial access type, $\mathrm{n}(\%)$ & & & 0.697 \\
\hline CVC & $30(48.4)$ & $37(45.1)$ & \\
\hline AVF or AVG & $32(51.6)$ & $45(54.9)$ & \\
\hline Duration of ESRD, years, mean \pm SD & $5.5 \pm 7.7$ & $7.4 \pm 8.9$ & 0.176 \\
\hline \multicolumn{4}{|l|}{ Co-existing medical conditions, n (\%) } \\
\hline Diabetes & $9(14.5)$ & $23(28.0)$ & 0.050 \\
\hline Stroke & $5(8.1)$ & $6(7.3)$ & 0.867 \\
\hline \multicolumn{4}{|l|}{ Baseline blood pressure therapy } \\
\hline Number of antihypertensives, mean \pm SD & $1.44 \pm 1.58$ & $2.03 \pm 1.25$ & 0.020 \\
\hline Patients on $>2$ antihypertensives, $\mathrm{n}(\%)$ & $25(41.0)$ & $52(65.8)$ & 0.003 \\
\hline
\end{tabular}

Table 3. Characteristics of patients with LVH regression and progression

\begin{tabular}{|c|c|c|c|}
\hline & $\begin{array}{l}\text { Regressors } \\
(\mathrm{n}=87)\end{array}$ & $\begin{array}{l}\text { Progressors } \\
(\mathrm{n}=57)\end{array}$ & $\mathrm{p}$ value \\
\hline Age, years, mean \pm SD & $44.2 \pm 12.1$ & $44.5 \pm 14.2$ & 0.881 \\
\hline $\mathrm{BMI}, \mathrm{kg} / \mathrm{m}^{2}$, mean $\pm \mathrm{SD}$ & $25.5 \pm 6.1$ & $25.3 \pm 6.4$ & 0.901 \\
\hline Type of renal replacement therapy prior to intensive hemodialysis, $n(\%)$ & & & 0.742 \\
\hline Chronic kidney disease not on dialysis & $24(27.6)$ & $17(29.8)$ & \\
\hline Renal transplantation & $20(23.0)$ & $13(22.8)$ & \\
\hline Initial access type, $\mathrm{n}(\%)$ & & & 0.122 \\
\hline CVC & $45(51.7)$ & $22(38.6)$ & \\
\hline AVF or AVG & $42(48.3)$ & $35(61.4)$ & \\
\hline Duration of ESRD, years, mean \pm SD & $6.9 \pm 8.6$ & $5.9 \pm 8.1$ & 0.488 \\
\hline Presence of LVH at baseline, $n(\%)$ & $43(49.4)$ & $39(68.4)$ & 0.024 \\
\hline LVM at baseline, $g$, mean \pm SD & $190.1 \pm 75.7$ & $205.8 \pm 62.7$ & 0.302 \\
\hline Hypertension & $71(81.6)$ & $51(89.5)$ & 0.200 \\
\hline Coronary artery disease & $9(10.3)$ & $8(14.0)$ & 0.502 \\
\hline Peripheral vascular disease & $6(6.9)$ & $3(5.3)$ & 0.692 \\
\hline Stroke & $8(9.2)$ & $3(5.3)$ & 0.385 \\
\hline \multicolumn{4}{|l|}{ Baseline blood pressure therapy } \\
\hline Number of antihypertensives, mean \pm SD & $1.65 \pm 1.52$ & $1.96 \pm 1.26$ & 0.209 \\
\hline Patients on $>2$ antihypertensives, $\mathrm{n}(\%)$ & $42(48.8)$ & $35(64.8)$ & 0.064 \\
\hline \multicolumn{4}{|l|}{ 1-Year blood pressure therapy } \\
\hline Number of antihypertensives, mean \pm SD & $0.69 \pm 0.91$ & $0.80 \pm 1.00$ & 0.536 \\
\hline Patients on $>2$ antihypertensives, $\mathrm{n}(\%)$ & $18(21.2)$ & $10(18.5)$ & 0.703 \\
\hline No antihypertensives or less than baseline, $\mathrm{n}(\%)$ & $69(81.2)$ & $44(81.5)$ & 0.964 \\
\hline
\end{tabular}


Table 4. Multivariate analysis for the development of LVH progression

\begin{tabular}{lllll}
\hline Variable & Unadjusted OR (95\% CI) & p value & Adjusted OR (95\% CI) & p value \\
\hline Age & $1.00(0.98-1.03)$ & 0.880 & $0.99(0.97-1.03)$ & 0.755 \\
Diabetes & $1.06(0.48-2.36)$ & 0.891 & $0.93(0.39-2.22)$ & 0.877 \\
Smoking history & $2.92(1.12-7.58)$ & 0.028 & $2.78(1.06-7.36)$ & 0.039 \\
LVH at baseline & $2.21(1.10-4.46)$ & 0.026 & $2.21(1.06-4.59)$ & 0.033 \\
\hline
\end{tabular}

Table 5. Cox proportional hazards analysis of the risk of the composite end point of death, technique failure and CV-related hospitalization

\begin{tabular}{lllll}
\hline Variable & Unadjusted OR (95\% CI) & p value & Adjusted OR (95\% CI) & p value \\
\hline LVH regressors vs. progressors & $0.51(0.26-0.99)$ & 0.050 & $0.42(0.21-0.84)$ & 0.014 \\
Diabetes & $3.25(1.62-6.53)$ & 0.001 & $2.78(1.32-5.82)$ & 0.007 \\
Age & $1.05(1.02-1.08)$ & 0.001 & $1.04(1.01-1.07)$ & 0.009 \\
\hline
\end{tabular}

Table 6. Cox proportional hazards analysis of the risk of the death

\begin{tabular}{lllll}
\hline Variable & Unadjusted OR (95\% CI) & p value & Adjusted OR (95\% CI) & p value \\
\hline LVH regressors vs. progressors & $0.24(0.08-0.77)$ & 0.017 & $0.20(0.06-0.67)$ & 0.009 \\
Diabetes & $2.78(0.93-8.35)$ & 0.069 & $2.74(0.85-8.86)$ & 0.093 \\
Age & $1.06(1.02-1.11)$ & 0.004 & $1.05(1.01-1.10)$ & 0.017 \\
\hline
\end{tabular}

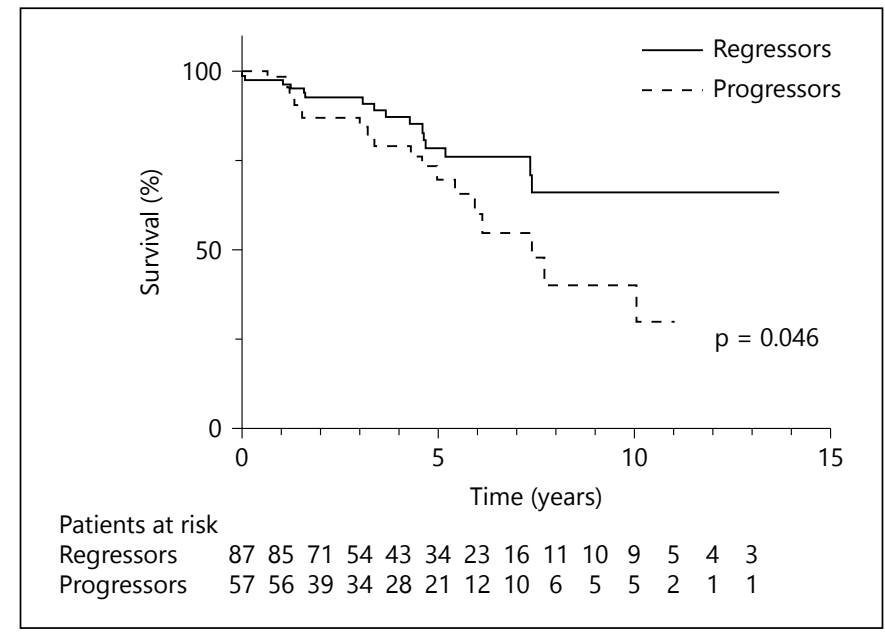

Fig. 2. Composite end point-free survival in LVH regressors and progressors. Regressors had a significantly lower risk of developing the composite end point.

mented by similar studies in patients on conventional hemodialysis, with essential hypertension and renal transplant recipients [4, 23-25, 27, 28].

There are many potential pathophysiologic mechanisms for worsened clinical outcomes with LVM progres-

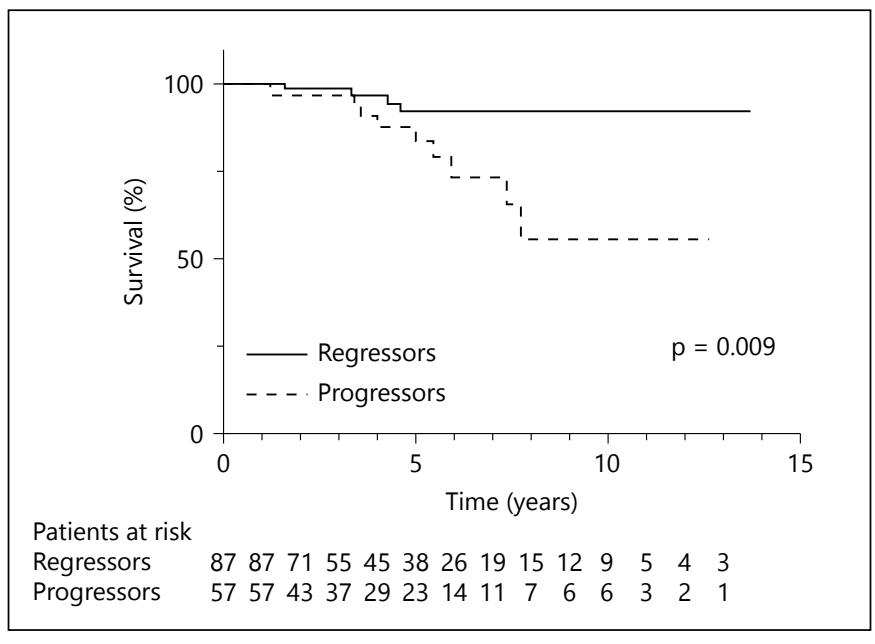

Fig. 3. Patient survival in LVH regressors and progressors. Regressors had a significantly lower risk of mortality.

sion. Indeed, there has been consistent evidence that progressive LVH and cardiac fibrosis leads to diastolic and systolic dysfunction with chamber dilation, disturbances in intraventricular conduction and changes in ventricular contractility secondary to neurohumoral activation due 
to sympathetic activation with increased risk of ventricular arrhythmias $[5,29]$. This may consequently predispose to cardiovascular events and sudden cardiac death, which are the leading causes of morbidity and mortality in dialysis patients [1]. In addition, augmenting dialysis frequency has been shown to reduce left and right ventricular volumes and to increase heart rate variability due to changes in vagal modulation of heart rate $[30,31]$. In fact, higher ventricular volumes and reduced heart rate variability have both been established as independent risk factors for mortality and cardiovascular events $[32,33]$.

Reduction of LVM with intensive frequent hemodialysis is likely multifactorial in the context of improved clearance, better control of systemic blood pressure and volume status and abnormalities of mineral metabolism. In fact, all these factors have been shown to improve with increased dialysis frequency and duration $[16,18,19,34$, $35]$. Studies have also demonstrated that intensive hemodialysis leads to downregulation of genes involved in cardiomyocyte apoptosis and fibrosis, decreased arterial stiffness and improved endothelial dysfunction $[36,37]$.

Our study does have limitations given its observational single-center nature. While the cohort included 144 patients on intensive hemodialysis, the overall sample size could have limited the significance of other potential risk factors for LVH regression. Another limitation is the use of a surrogate composite end point as the primary outcome, which was chosen given the low number of deaths in the follow-up period. The lower mortality rates could be potentially explained by the fact that we excluded patients who died within the first year of initiation of dialysis, a period of increased mortality and patients with missing echocardiographic examinations. In fact, in the excluded patients, there were 16 deaths $(21.9 \%)$ and 10 technique failures (13.7\%). Thus, it is possible that the effect size may be underestimated given that patients who died or had technique failure did not have follow-up echo- cardiograms. Furthermore, technique failure was included in the composite outcome as it is a surrogate of frailty and comorbid burden. Nonetheless, even when evaluating mortality alone, the positive impact of LVH regression remained significant. Moreover, the use of echocardiography as the imaging modality may have led to overestimation of LVM, and in fact, cardiac MRI would have been a preferred modality [38]. We also did not evaluate the impact of ventricular volume changes. Furthermore, it should be noted that the true hemodialysis frequency and duration could differ from the prescribed regimen given the operator dependence; this could potentially influence our results and is difficult to account for.

Nonetheless, this is the first study evaluating the impact of LVM regression on mortality and cardiovascular events in a cohort of patients on intensive hemodialysis. Indeed, while previous studies have shown that regression of LVM is certainly feasible with longer frequent hemodialysis, we identified that progression or development of LVH was an independent risk factor for mortality, technique failure and adverse cardiac events. In summary, regression of LVH, regardless of the intervention, leads to favorable clinical outcomes in patients on intensive hemodialysis and should be considered a crucial goal. The importance of serial monitoring of LVM is also emphasized. A prospective multi-center study evaluating the impact of changes in LVM would allow for better identification of risk factors for $\mathrm{LVH}$ progression and potential therapeutic strategies.

\section{Disclosure Statement}

This study is funded through a Baxter extramural grant. Dr. Christopher T. Chan holds the R. Fraser Elliot Chair in Home Dialysis and consulted for Baxter Inc., NxStage Inc., and Intelomed Inc. Dr. Emilie Trinh is a recipient of the University Health Network - Baxter Home Dialysis Fellowship.

\section{References}

1 Collins AJ, Foley RN, Gilbertson DT, Chen SC: United States renal data system public health surveillance of chronic kidney disease and end-stage renal disease. Kidney Int Suppl (2011) 2015;5:2-7.

2 Charytan D: Is left ventricular hypertrophy a modifiable risk factor in end-stage renal disease. Curr Opin Nephrol Hypertens 2014;23: 578-585.

3 Levin A, Singer J, Thompson CR, Ross H, Lewis M: Prevalent left ventricular hypertrophy in the predialysis population: identifying opportunities for intervention. Am J Kidney Dis 1996;27:347-354.

4 Zoccali C, Benedetto FA, Mallamaci F, Tripepi G, Giacone G, Stancanelli B, Cataliotti A, Malatino LS: Left ventricular mass monitoring in the follow-up of dialysis patients: prognostic value of left ventricular hypertrophy progression. Kidney Int 2004;65:1492-1498.

5 Glassock RJ, Pecoits-Filho R, Barberato SH: Left ventricular mass in chronic kidney disease and ESRD. Clin J Am Soc Nephrol 2009; 4(suppl 1):S79-S91.
6 Bansal N, Keane M, Delafontaine P, Dries D, Foster E, Gadegbeku CA, Go AS, Hamm LL, Kusek JW, Ojo AO, Rahman M, Tao K, Wright JT, Xie D, Hsu CY; CRIC Study Investigators: A longitudinal study of left ventricular function and structure from CKD to ESRD: the CRIC study. Clin J Am Soc Nephrol 2013;8:355-362.

7 Foley RN, Parfrey PS, Harnett JD, Kent GM, Martin CJ, Murray DC, Barre PE: Clinical and echocardiographic disease in patients starting end-stage renal disease therapy. Kidney Int 1995;47:186-192. 
8 Hayashi T, Kimura T, Yasuda K, Obi Y, Sasaki K, Iio K, Miyasato K, Kamimura T, Kitamura H, Tsubakihara Y, Rakugi H, Isaka Y: Prognostic significance of left ventricular hypertrophy observed at dialysis initiation depends on the pre-dialysis use of erythropoiesis-stimulating agents. Clin Exp Nephrol 2013;17:294-303.

9 Harnett JD, Kent GM, Barre PE, Taylor R, Parfrey PS: Risk factors for the development of left ventricular hypertrophy in a prospectively followed cohort of dialysis patients. J Am Soc Nephrol 1994;4:1486-1490.

10 Park CW, Shin YS, Kim CM, Lee SY, Yu SE, Kim SY, Choi EJ, Chang YS, Bang BK: Increased c-reactive protein following hemodialysis predicts cardiac hypertrophy in chronic hemodialysis patients. Am J Kidney Dis 2002; 40:1230-1239.

11 Nitta K, Akiba T, Uchida K, Otsubo S, Otsubo Y, Takei T, Ogawa T, Yumura W, Kabaya T, Nihei H: Left ventricular hypertrophy is associated with arterial stiffness and vascular calcification in hemodialysis patients. Hypertens Res 2004;27:47-52.

12 Bossola M, Tazza L, Vulpio C, Luciani G: Is regression of left ventricular hypertrophy in maintenance hemodialysis patients possible? Semin Dial 2008;21:422-430.

13 London GM: Left ventricular hypertrophy: why does it happen? Nephrol Dial Transplant 2003;18(suppl 8):viii2-viii6.

14 Foley RN, Parfrey PS, Kent GM, Harnett JD, Murray DC, Barre PE: Long-term evolution of cardiomyopathy in dialysis patients. Kidney Int 1998;54:1720-1725.

15 Foley RN, Curtis BM, Randell EW, Parfrey PS: Left ventricular hypertrophy in new hemodialysis patients without symptomatic cardiac disease. Clin J Am Soc Nephrol 2010;5:805813.

16 Chan CT, Floras JS, Miller JA, Richardson RM, Pierratos A: Regression of left ventricular hypertrophy after conversion to nocturnal hemodialysis. Kidney Int 2002;61:2235-2239.

17 Susantitaphong P, Koulouridis I, Balk EM, Madias NE, Jaber BL: Effect of frequent or extended hemodialysis on cardiovascular parameters: a meta-analysis. Am J Kidney Dis 2012;59:689-699.

18 Walsh M, Manns BJ, Klarenbach S, Tonelli M, Hemmelgarn B, Culleton B: The effects of nocturnal compared with conventional hemodialysis on mineral metabolism: a randomized-controlled trial. Hemodial Int 2010; 14:174-181.

19 Hanly PJ, Pierratos A: Improvement of sleep apnea in patients with chronic renal failure who undergo nocturnal hemodialysis. N Engl J Med 2001;344:102-107.
20 Culleton BF, Walsh M, Klarenbach SW, Mortis G, Scott-Douglas N, Quinn RR, Tonelli M, Donnelly S, Friedrich MG, Kumar A, Mahallati H, Hemmelgarn BR, Manns BJ: Effect of frequent nocturnal hemodialysis vs conventional hemodialysis on left ventricular mass and quality of life: a randomized controlled trial. JAMA 2007;298:1291-1299.

21 Friesen T, Jassal DS, Zhu M, Eng F, Rigatto C, Tangri N, Sood MM, Karlstedt E, Premecz S, Komenda P: Cardiovascular remodeling during long-term nocturnal home hemodialysis. Clin Exp Nephrol 2015;19:514-520.

22 FHN Trial Group, Chertow GM, Levin NW, Beck GJ, Depner TA, Eggers PW, Gassman JJ, Gorodetskaya I, Greene T, James S, Larive B, Lindsay RM, Mehta RL, Miller B, Ornt DB, Rajagopalan S, Rastogi A, Rocco MV, Schiller B, Sergeyeva O, Schulman G, Ting GO, Unruh ML, Star RA, Kliger AS: In-center hemodialysis six times per week versus three times per week. N Engl J Med 2010; 363:2287-2300.

23 London GM, Pannier B, Guerin AP, Blacher J, Marchais SJ, Darne B, Metivier F, Adda H, Safar ME: Alterations of left ventricular hypertrophy in and survival of patients receiving hemodialysis: follow-up of an interventional study. J Am Soc Nephrol 2001;12:2759-2767.

24 Pierdomenico SD, Cuccurullo F: Risk reduction after regression of echocardiographic left ventricular hypertrophy in hypertension: a meta-analysis. Am J Hypertens 2010;23:876881.

25 Paoletti E, Bellino D, Signori A, Pieracci L, Marsano L, Russo R, Massarino F, Ravera M, Fontana I, Carta A, Cassottana P, Garibotto G: Regression of asymptomatic cardiomyopathy and clinical outcome of renal transplant recipients: a long-term prospective cohort study. Nephrol Dial Transplant 2016;31: 1168-1174.

26 Lang RM, Badano LP, Mor-Avi V, Afilalo J, Armstrong A, Ernande L, Flachskampf FA, Foster E, Goldstein SA, Kuznetsova T, Lancellotti P, Muraru D, Picard MH, Rietzschel ER, Rudski L, Spencer KT, Tsang W, Voigt JU: Recommendations for cardiac chamber quantification by echocardiography in adults: an update from the American society of echocardiography and the European association of cardiovascular imaging. J Am Soc Echocardiogr 2015;28:1-39.e14.

27 Bang CN, Devereux RB, Okin PM: Regression of electrocardiographic left ventricular hypertrophy or strain is associated with lower incidence of cardiovascular morbidity and mortality in hypertensive patients independent of blood pressure reduction - a LIFE review. J Electrocardiol 2014;47:630-635.
28 Devereux RB, Wachtell K, Gerdts E, Boman K, Nieminen MS, Papademetriou V, Rokkedal J, Harris K, Aurup P, Dahlöf B: Prognostic significance of left ventricular mass change during treatment of hypertension. JAMA 2004;292:2350-2356.

29 Ritz E: Left ventricular hypertrophy in renal disease: beyond preload and afterload. Kidney Int 2009;75:771-773.

30 Chan CT, Chertow GM, Daugirdas JT, Greene TH, Kotanko P, Larive B, Pierratos A, Stokes JB; Frequent Hemodialysis Network Daily Trial Group: Effects of daily hemodialysis on heart rate variability: results from the frequent hemodialysis network (FHN) daily trial. Nephrol Dial Transplant 2014;29:168-178.

31 Chan CT, Greene T, Chertow GM, Kliger AS, Stokes JB, Beck GJ, Daugirdas JT, Kotanko P, Larive B, Levin NW, Mehta RL, Rocco M, Sanz J, Yang PC, Rajagopalan S; Frequent Hemodialysis Network Trial Group: Effects of frequent hemodialysis on ventricular volumes and left ventricular remodeling. Clin J Am Soc Nephrol 2013;8:2106-2116.

32 La Rovere MT, Bigger JT Jr, Marcus FI, Mortara A, Schwartz PJ: Baroreflex sensitivity and heart-rate variability in prediction of total cardiac mortality after myocardial infarction. ATRAMI (autonomic tone and reflexes after myocardial infarction) investigators. Lancet 1998;351:478-484.

33 Zoccali C, Benedetto FA, Mallamaci F, Tripepi G, Giacone G, Cataliotti A, Seminara G, Stancanelli B, Malatino LS: Prognostic value of echocardiographic indicators of left ventricular systolic function in asymptomatic dialysis patients. J Am Soc Nephrol 2004;15: 1029-1037.

34 Lindsay RM, Alhejaili F, Nesrallah G, Leitch R, Clement L, Heidenheim AP, Kortas C: Calcium and phosphate balance with quotidian hemodialysis. Am J Kidney Dis 2003;42(1 suppl):24-29.

35 Nesrallah G, Suri R, Moist L, Kortas C, Lindsay RM: Volume control and blood pressure management in patients undergoing quotidian hemodialysis. Am J Kidney Dis 2003;42(1 suppl):13-17.

36 Chan CT, Li GH, Valaperti A, Liu P: Intensive hemodialysis preserved cardiac injury. ASAIO J 2015;61:613-619.

37 Ly J, Chan CT: Impact of augmenting dialysis frequency and duration on cardiovascular function. ASAIO J 2006;52:e11-e14.

38 Missouris CG, Forbat SM, Singer DR, Markandu ND, Underwood R, MacGregor GA: Echocardiography overestimates left ventricular mass: a comparative study with magnetic resonance imaging in patients with hypertension. J Hypertens 1996;14:1005-1010. 